\title{
A Formação Técnico-Profissional para uma Organização Hospitalar de alto Padrão
}

\author{
Dr. Gennyson amado \\ (Chefe da Divisão de Assistência Médico. \\ Hospitalar do IPASE)
}

\begin{abstract}
O presente trabalho, elaborado especialmente para o 1. Congresso Nacional de Hospitais e a $1 .^{\text {a }}$ Conferência Nacional de Diretores de Serviço de Assistência Hospitalar, que se reunirão no próximo mês nesta Capital, é da autoria de um dos mais profundos conhecedores, no Brasil, do importante problema aqui discutido. O Dr. GENNYSON AMADO foi durante vários anos Diretor do Hospital dos Servidores do Estado e é Membro do Conselho Deliberativo da Associação Brasileira de Hospitais.
\end{abstract}

$$
* * *
$$

$\mathrm{O}$

tema que nos propomos desenvolver será considerado, essencialmente, com o sentido objetivo da sua aplicação às condições reais do meio brasileiro e às peculiaridades impostas pelas contingências regionais.

São bem conhecidas as normas e a sistemática estabelecidas pelos padrões americanos e europeus, concernentes ao capitulo considerado.

Essas, hão de diferir em relação as nosso país, senão nas diretrizes de base, uniformes na colimação do escopo universal que visa à correta preparação do pessoal técnico, mas nas características em que se devem realizar e ser atingidas entre nós.

Se se estabelecer um paralelo entre a organização hospitalar das nações que atingiram um grau de evolução experimental, aferido em expoentes elevados do aprimoramento técnico, na prática médico-assistencial, e a dos países em que a conquista dêsse grau ainda não foi alcançada, há de se fixar certamente, uma diferenciação dos processos aplicados em umas e em outros, na objetivação dêsse firn.

Essa diferenciação se evidencia, bàsicamente, no mesmo plano em que se exprimem os desníveis econômicos. O aprimoramento técnico de uma comunidade, é reflexo do seu progresso econômico. Qualquer conceituação de ordem material, e a técnica o é predominantemente, depende da base econômica que a funde e a sustenta. Grau técnico elevado se obtém com recursos proporcionais. Onde há melhores condições materiais o seu desenvolvimento 
se processa adequadamente. Não prescinde entretanto, a formação técnica, do domínio da cultura. $\mathrm{O}$ estudo, a pesquisa a laboração e a elaboração, a prática da constância, são imprescindíveis para a doutrinação da técnica. Mas, para a sua integração há que se manipular instrumentos do trabalho técnico, com o seu pleno conhecimento. A doutrina adequa o espírito ao assenhoramento da técnica; esta se incorpora, no manuseio dos seus princípios, das suas regras, dos métodos de sua execução.

Para tanto, se requer a oficina, o laboratório, os meios concretos que levam ao aperfeiçoamento técnico.

Nos países onde o índice de assistência médicc-hospitalar se exprime nas melhores fórmulas da relação leito hospitalar - massa demográfica, as exigências para a formação técnica são atendidas, evidentemente. Quer pelo volume de oportunidade oferecido, quer pela atração que exercem as profissões relacionadas com o exercício médico-assistencial, os organismos de preparação e treinamento dêsses profissionais, apresentam estruturas bem definida, constituindo entidades modelares.

O seu número se multiplica nas nações de padrão econômico geral elevado, criando facilidades ao aprendizado e à prática profissionais, propiciando, ao mesmo tempo, a padronização dos métodos de trabalho aos níveis exigíveis.

É o que não ocorre no nosso meio, onde, pela não existência daquelas condições, rareiam os núcleos do preparo técnico adequado e não se acham ainda constituídos em sistema definido, os preceitos que regulam uma formação técnica apurada.

O "deficit" de leitos hospitalares acentuado, no que concerne à massa da população brasileira, agravado na expressão nosográfica do país; a rala fração percentual de profissionais formados para o exercício médico assistencial; a baixa retribuição oferecida, no comum, ao trabalho técnico; a não instî́uição de uma política hospitalar brasileira, fundada nas nossas realidades e estruturada em planejamentos e diretrizes essencialmente técnicas, são condiçöes que têm retardado o progresso positivo das instituições hospitalares, no nosso meio, no que concerne a constituição das suas equipes técnicas.

A estrutura política institucional brasileira tem produzido igualmente, efeitos sensíveis na evolução do progresso das profissões técnicas entre nós.

Enquanto nos países onde mais acentuada tem sido essa evolução, as células que propulsionam os organismos técnicos se acham na órbita da iniciativa privada, são geralmente do domínio do Estado, nas nações de padrão econômico débil, as instituições onde se formam e se aprimoram os técnicos.

Tal concentração, resulta, evidentemente, anti-econômica, a par de ensejar o desvirtuamento das finalidades dessas instituições em países como o nosso de imaturidade política, permitindo a sua utilização na prática da política individualista, ao invés de salutar política da formação e do aprimoramento técnico das gerações brasileiras, tão bem dotadas de qualidades inatas como é reconhecido, e tão ansiosas por se votarem à cultura da técnica de que tanto carecem as ricas fontes dinâmicas e estáticas do país. 
A burocratização, vício estatal por excelência, atribui configuração de simples repartição às organizações destinadas a laboração técnica, subtraindolhes, de ordinário, as condições adequadas ao trabalho daquela expressão.

A legislação que rege a atividade burocrática do Estado é pràticamente, a mesma que regula a atividade técnica, de idêntica filiação.

Esta, pelas características em que se desenvolve, nos planos da sua aplicação, requer enquadramento funcional diferenciado, como diferenciados são os métodos em que se realiza.

Não teremos progredido o suficiente, no campo da técnica, senão com derivação perdulária de esforços, sem que se vençam as conviç̧ões que presidem a nossa instituição política, nêsse particular.

Nela reside um dos baluartes que defrontam as forç̧as renovadoras que vêm no aprimoramento técnico, a satisfação dos ideais mais benfazejos para a Nação Brasileira.

Este Congresso, que desenvolve temário cuja pedra angular se constitui em traçar a política hospitalar brasileira, inscrevera certamente, nas diretrizes dessa política, a racionalização, à luz das nossas realidades, a metodização das normas que devem reger a atividade técnica específica de que cogita.

OS NÚCLEOS DE FORMAÇÃo TÉCNICA E A NECESSIDADE DE SUA INTEGRAÇÃo EM SISTEMA COORDENADO

Na discriminação das causas que definem a situação em que nos encontramos em face da formação do pessoal que se destina ao serviço do hospital, é de se considerar como de importância capital no sistema ẹm que deve se assentar as bases reais dessa formação, os núcleos de preparo profissional fêsse pessoal, a escola, o hospital.

O nível universitário é exigido, de ordinário para os técnicos que servern no Hospital. Médicos, Odontólogos, Farmacêuticos, Enfermeiras, Assistentes Sociais e etc, são ordens profissionais de grau universitário.

Não obstante a conceituação de que merecidamente gozam as escolas dêsse grau, a nossa formação profissional universitária, predominantemente teórica, não faculta o exercício de atividade manipuladora para a criação de base técnica, no que se refere ao exercício da função médica ou para-médica. A escassez de oficinas e de aparelhagem apropriada, em volume correspon, dente às necessidades, a quase ausência de condições que estimulem as vocações marcadas, a precariedade material de muitos dos núcleos técnico-educacionais, têm respondido pelas ingentes dificuldades opostas ao pragmatismo de uma preparação técnica rigorosa, na formação de pessoal hospitalar, de quaisquer categorias e hierarquias.

O ápice de uma carreira técnica se atinge, não só através do conhecimento das doutrinas que formam a consciência profissional, como do desenvolvimento das qualidades que aprimoram o exercício prático das tarefas a cumprir nessa profissão. Daí, ser necessária, não apenas a incorporação de conhecimentos teóricos abalisados, mas a destreza de manipulação, adquirida na prática constante atinente ao desempenho da execução técnica. $O$ culto 
harmônico de uma e de outra, são atributos do técnico, considerado na acepção exata.

A técnica, segundo BERGSON, é a adaptação do homem às realidades práticas. Para tanto, para essa adaptação, há que se prover e dispor não apenas o espírito, de elementos de elucidação e informação que the permitem o conhecimento e o domínio dessas realidades, mas também os meios objetivos de exercer êsse domínio.

Por outro lado, os campos do aprendizado prático não tem sido fertilinecessàriamente, a escola das concepções doutrinárias e a oficina do exercício prático.

No nosso meio, a formação técnica do pessoal destinado a servir no hospital, carece da integração dêsse binômio, assumindo aspecto particularistas e especiais. As escolas não se moldam ainda, a bem dizer, em sistemas onde a doutrina e a sua aplicação, tenham as mesmas paridades, a primeira predominando, de ordinário, sôbre a segunda nos planos de ensinu.

Por outro lado, os campos do aprendizado prático não têm sido fertilizados para propiciar os frutos de uma semeadura fértil e depurada, através de uma experimentação bem orientada.

Decorre dessa circunstância, ser a própria séde da atividade hospitalar, - núcleo básico da formação técnica especializada, para onde acorrem os egressos das escolas, buscando espontâneamente a complementaçao da sua habilitação profissional. Alí, no contacto objetivo com os misteres específicos, é que vão aprimorar a sua desenvoltura técnica, muitas vêzes autodidatismo quando o centro hospitalar não apresenta condições para o seu treinamento, quando o hospital não oferece subjetiva e objetivamente, atmosfera para êsse aprendizado, quando, enfim, não possui o hospital o sentido de escola ativa que deve ser.

Assim como há entidades escolares destinadas à formação de profissionais que se destinam ao serviço hospitalar, devem, igualmente, ser constituídos, nos hospitais, centros de treinamento e aprimoramento dêsses profissionais, num sistema articulado com aquelas entidades.

Não basta, por exemplo, que uma enfermeira, no seu curso normativo, estagie em serviços do hospital, cumprindo o programa que ali the fôr traçado. O mesmo se aplica a qualquer outra categoria funcional que se enquadram no exercício hospitalar.

\section{PREPARAÇÃO DO PESSOAL TÉCNICO NO HOSPITAL}

Necessário se faz que o hospital esteja preparado para oferecer condições ao aproveitamento dêsse aprendizado. Terreno propício, orientação apropriada, participação direta no interêsse da formação do profissional, são fatores a serem atendidos pelo hospital como célula do organismo funcional que processe ensino útil ao técnico que se destina ao seu serviço. Daí, a necessidade do estabelecimento nos hospitais, de núcleos de aperfeiçoamento profissional, bem estruturados, que assegurem a execução do papel que o hospital moderno representa como escola ativa, complementando o ensino ministrado nas unidades escolas, especializadas nesse campo de ação. 
A imprescindibilidade de articular o hospital no esquema de ensino técnico de carreiras a que se relacione atividades aí exercidas, se realça quando o problema se projeta sôbre as escolas que não visam a formação específica, exclusiva do técnico para o hospital, como ocorre, por exemplo, com as escolas de Serviço Social que, preparando assistentes sociais para o exercício multiforme da ação social, não o faz privativamente, para aquêle que se aplica no hospital.

O mesmo se estenderia às escolas de Nutrólogos, Dietistas, e etc.. Entretanto, as peculiaridades do desempenho de qualquer atividade discriminada no hospital, exigem um sentido de unidade coorporificada, que obriga uma formação institucional adequada, sem a qual sacrificada seria, certamente, a configuração do bom padrão assistencial.

Para a integração do técnico na órbita do hospital, sòmente o próprio hospital proporciona os meios para que ela se realize.

Deve, portanto, o hospital aparelhar-se para dar cumprimento a esta atribuição, talvez aquela que melhor defina a concepção do hospital moderno.

Entre nós, urge se proceder a instituição dêsse sistema pedagógico na formação do pessoal hospitalar.

Embora se haja atingido uma sensível melhoria nos métodos de ensino técnico no país; ainda que se tenham acrescido as unidades que ministram êsse ensino, as exigências prementes das organizações hospitalares, o número avultado de profissionais habilitados que se requer para o preenchimento dos quadros funcionais dessas entidades, estão a indicar a imperativa necessidade de se estabelecer rumos práticos e seguros no preparo técnico daquêles que se destinam aos serviços do hospital.

A evolução que se vem registrando no panorama da assistência hospitalar no Brasil, refletida na extensão da rêde de suas unidades exige se voltem para a cultivação do elemento humano categorizado, aquêles que enfeixam qualquer responsabilidade na dotação cultural e na composição das nossas elites, ligadas a atividades hospitalares.

Se projetarmos, em paralelo, o desenvolvimento numérico dos núcleos hospitalares do País à hora atual, e as condições de preparo técnico do pessoal que nêles serve ou de que necessitam, ter-se-á, de um lado, o progresso material evidente e do outro a deficiência quantitativa e qualitativa.

Num plano, a arquitetônica, admirável já, na concepção do hospital moderno; no outro, a precariedade volumétrica e específica.

Alguns belos e bem construídos barcos sem tripulantes suficientes e capazes para o seu govêrno e rumos seguros.

A disparidade patente no paralelo estabelecido, tende, entretanto, a encontrar o seu nivelamento, as causas do desiquilíbrio assinalado, sendo, elas próprias, um fator do seu ajustamento.

Maior número de unidades de trabalho e mais sedutoras condições passam a ser oferecidas aos que se candidatam às profissões ligadas à atividade hospitalar, indicando a oportunidade de se amoldar o sistema de formação técnica nas profissões referidas, o quanto antes, em dar-lhe estrutura que atenda ao correto preparo dêsses profissionais. 
Considerados como sistema isolados, tanto centros de ensino especializado, como hospitais funcionais existentes, capacitam essa formação. De fato, cursos de organização e administração hospitalar, escolas de enfermagem, de serviço social, de nutrólogos e dietistas, e etc., bem como hospitais erigidos segundo os preceitos modernos da técnica hospitalar, arquitetônica e organizacional, a constituição, nos núcleos de bom padrão funcional, de uma consciência profissional responsável, entre os que exercem atividade médico-assistencial, podem assegurar um futuro promissor na composição técnica dos quadros atuantes nas nossas organizações hospitalares.

Necessário se faz, todavia, coordenar e regimentar os meios e as diretrizes que devem conduzir e presidir a formação técnica do pessoal destinado a específica atividade no hospital.

A coordenação dos meios deverá se efetuar através da padronização pedagógica dos núcleos de ensino e de treinamento.

A regimentação das diretrizes, deve se processar pela codificação dos cânones que regulam a formação técnica do pessoal que se destina ao serviço no hospital.

Escolas em que se prepara a consciência profissional, onde se ministram conhecimentos doutrinários, onde se exercita a prática, se adestra o espírito e se modela a sensibilidade para o desempenho de misteres tão diferenciados, devem possuir condições reguladas e expressas que permitam a formação integral do técnico hospitalar, fundindo-se num sistema integrativo com o próprio hospital. Necessário se impõe a articulação complementar da escola das concepções doutrinárias com a escola das aplicações práticas. Devem, assim, ser revistas a composição, as normas de funcionamento, os currículos dos organismos onde se professa o ensino profissional relacionado com o exercício hospitalar, para a uniformização dos métodos, para se dispor o sistema de integração referido, para oferecer-lhes campos onde encontrem um fator comum de eficiência didática na formação psicológica e técnica, nos melhores padrões, daquêles que vão arcar com as responsabilidades que envolvem o ministério hospitalar.

Se nos grandes centros já se esboça a aplicação dêsse sistema, por imperativo das realidades, mais uma razão para concretizar-se as suas bases armar-se a sua estrutura definitiva.

\section{TREINAMENTO DO PESSOAL TÉCNICO E LEIGO NO HOSPITAL}

Capítulo de destacada importância nas disposições a serem assumidas no planejamento para o aprimoramento do pessoal hospitalar, se nos afigura a instituição de regime de treinamento em serviço.

Em face do agudo "deficit" de elementos técnicos, capazes de atenderen ao movimento dos quadros hospitalares, desde os postos de chefia, ou mesmo daquêles que, não exercendo atividades pròpriamente de caráter técnico, devem se situar no sistema funcional unitário que constitui o hospital de bom padrão, é de se instituir, de imediato, nas organizações do gênero, regime de treinamento constante a ser cumprido pelo pessoal em serviço. 
Não há quem ignore ser elevado o percentual de empregados nos hospitais, sem condições de habilitação ou preparo, para os serviços que desempenham. Essa impressão se recolhe em tôdas as categorias funcionais, de um modo geral. Entretanto, qualquer que seja o tipo de atividade exercida no hospital, se requer do seu executante, a par do conhecimento básico das suas atribuiçŏes, uma soma de noções funcionais inerentes à órbita institucional que o hospital representa. Desde o sentido humanitário que se implica no "serviço do hospital", até as qualidades morais que se exigem de um membro da comunidade hospitalar; desde a prática consciente da ética profissional por quem quer que trabalhe no hospital, até a propriedade pessoal em têrmos gerais, - as unidades humanas que compõem a equipe funcional do hospital, devem se revestir de uma gama de atributos diferenciados, grande parte dos quais, só investem após instruídos do seu valor e exercitados na sua incorporação.

Assim e a bem dizer, não são poucos aquêles que, servindo no hospital, carecem de formação adequada à concepção real da séde do seu trabalho, - hospital, - de características especiais, que envolvem aspectos próprios e diversos de qualquer outra entidade de trabalho, abrigando interêsses alheios inalienáveis, quase sempre filiados aos recessos privados da sua clientela.

A iniciação do treinamento do pessoal em serviço, pois, compreenderá a instrução dos grupos sôbre a concepção do hospital, como séde institucional do seu trabalho.

A filiação da unidade humana do trabalho no hospital à sua boa conceituação, é fase importante do treinamento por ser a do preparo psicológico que vai constituir a "consciência" funcional. A doutrinação a êsse propósito deverá ser constante, nas reuniões de grupo, nos contactos diretos, na associação dos resultados obtidos, no incentivo, na valorização do trabalho e daquêle que o executa. Os efeitos dêsse procedimento são positivos e excedem, geralmente, as expectativas.

Paralelamente, desenvolve-se o aprimoramento funcional, através da orientação e assistência constante dos chefes e graduados do grupo, na prática exercida. Essa modalidade de treinamento, simples, exequível, agradável para o orientador que se investe de qualificação e para quem recebe a instrução, por sentir não ser anônima a sua produção, pode ser aplicada a todos os grupos, inclusive aos de categoria funcional inferior, pessoal de cozinha, copa, serviçais em geral. Chefes e graduados, prèviamente formados e treinados, podem executá-la com eficiência. Contudo, é proveitosa a participação pessoal periódica dos próprios diretores da instituição, nessas reuniōes gerais dos grupos.

\section{UMA EXPERIENCIA DA INSTITUIÇÃO DE UM PROGRAMA DE APRIMORAMENTO DO PESSOAL HOSPITALAR}

Temos vívida experiência nesse aprticular e de há muito vimos introduzindo e aplicando êsse processo nas organizações assistenciais que temos dirigido. Consideramos realmente de fundamental importância e efeito, o estabelecimento do regime permanente, compulsório, de treinamento do pessoal em serviço no hospital. 
No Hospital dos Servidores do Estado, por exemplo, tivemos ensejo, quando na sua direção, de abrir largo campo para a execução de planejamento visando o constante adestramento de quantos ali exercem atividade. Inscrevemos, como capítulo essencial, no programa de administração, o aprimoramento dos servidores, dentro dos diferentes grupos funcionais a que se achavam filiados.

À já categorizada equipe de médicos que ali servia, proporcionamos novos meios de cultivação, instalando e equipando laboratórios experimentais de medicina e cirurgia, estimulando vocações, incentivando a pesquisa científica e oferecendo campo à apuração técnica, através da prática experimental. Preciosos trabalhos foram ali produzidos.

Fomentamos as atividades do Centro de Estudos, elevando ao dôbro a sua dotação orçamentária (um milhão de cruzeiros), criando novos setores, incluindo nos programas da sua atuação, a participação dos serviços do Arquivo Médico e Estatístico, Social, Dietética e de Enfermagem. Além de dotarmos a Biblioteca e tôdas as unidades do Centro de Estudos de melhorias diversas, criamos Departamento de Documentação dotado de cinematografia especializada à côres, desenhos e fotografias técnicas, para melhor coordenar os registros científicos do Hospital.

Promovemos, após sete anos de seu funcionamento, a 1 . $^{\text {a }}$ Assembléia Médica do Hospital dos Servidores do Estado, destinada a revelar a experiência daquele centro de atividades científicas em todos os quadrantes da sua atuação, dela participando todos os seus Serviços, desde os Clínicos e Cirúrgicos aos de natureza auxiliar. As teses e trabalhos em número de cento e vinte e nove, expostos e debatidos em vários dias consecutivos em sessões públicas, espelharam a rica produtividade ali operada no âmbito técnico e cultural.

Considerando o que representa para a formação post-graduada dos jovens médicos egressos das universidades, o estágio em núcleos de maior desenvolvimento, duplicamos as oportunidades oferecidas no regime de residência aos recém formados provindos de todos os recantos do país, os quais treinados e atualizados em centro de incontestável padrão técnico elevado, poderão amanhã, muito beneficiar as populações brasileiras do interior, quando de regresso aos seus rincões.

O regime de bolsas de estudo post-graduado, sobretudo no sistema de residência no hospital, que vemos com satisfação ganhar terreno na evolução do preparo profissional no país, é sem dúvida uma diretriz a ser aplicada amplamente nos rumos da política hospitalar brasileira, no capítulo relacionado com a constituição das equipes técnicas do hospital.

No H.S.E. estendemos essa diretriz a outras categorias funcionais. Enfermeiras do Hospital realizaram estágio de um ano em escola paulista de enfermagem obstetra. Técnicos em laboratório igualmente, foram encaminhados a centros de São Paulo para fins de especialização. Ao deixarmos a direção daquele nosocômio, havíamos estabelecido os primeiros entendimentos com o Serviço Especial de Saúde Pública para o intercâmbio de enfermeiras brasileiras e norte-americanas. 
Completando o círculo de unidades destinadas ao melhor preparo do pessoal técnico do Hospital, utilizando a célula hospitalar como escola ativa conforme o concebemos, fundamos e equipamos com o atendimento rigoroso das exigências didáticas correspondentes, a Escola de Auxiliares de Enfermagem do Hospital dos Servidores do Estado, dispondo as normas do seu funcionamento em moldes a facultar a formação profissional integral, de quantos por ali passarem. A par dos cursos normativos, destinamos àquela Escola uma participação preponderante nos planos de aperfeiçoamento funcional e ético dos numerosos grupos que no Hospital, desempenham tarefas auxiliares.

Mas, ao nosso ver, e como já o fizemos sentir, a preocupação do esmero do pessoal que serve no hospital de alto padrão, não deve se restringir àqueles que desenvolvem tarefa especificamente técnica, e sim, se aplicar às demais categorias que interferem no funcionamento da entidade, considerada esta como uma unidade acional a serviço de um fim definido.

Daí, havermos conduzido o nosso planejamento no Hospital dos Servidores do Estado no sentido da sua aplicação em qualquer departamento onde um conjunto de pessoas realize trabalho classificado. Assim, incluímos naquele plano, todos os grupos do Hospital.

Reuniões de grupos, supervisionadas; debates, preleções, observações e análise direta da execução das tarefas, exame objetivo das causas de improdutividade, estímulo, assistência interessada aos deficitários por insuficiência básica de formação; criação de atmosfera propícia ao rendimento funcional consciente, rigoroso e justo critério no louvor e na punição, foram os instrumentos utilizados na execução do plano elaborado, de cuja efetivação participamos pessoal e interessadamente.

Foi estabelecida, para os grupos de nível intelectual compatível, a elaboração de trabalhos por elementos do próprio grupo para explanação e díscussão perante os componentes dos mesmos, em reuniões às quais assistíamos nós próprios, os membros do Centro de Estudos, atuando como coordenadores. Assumiram particular interêsse, no caso, os temas proferidos pelo Corpo de Enfermagem que, além das reunióes destinadas aos assuntos de rotina dos serviços, se congregava para apreciação de matéria relativa à enfermagem técnica.

Não se desprezou, no objeto daquele plano, o enquadramento do pessoal burocrata. Assim, tivemos oportunidade de instituir bolsas de estudos para funcionários do Hospital, em cursos de aperfeiçoamento da Fundação Getúlio Vargas e do Departamento Administrativo do Serviço Público. Por outro lado, promovemos aulas e conferências no próprio Hospital, administradas por professôres da Escola Brasileira de Administração Pública, para os ocupantes de cargos de chefia e para as equipes dos serviços administrativos.

Visando atrair o interêsse do pessoal para os hábitos do constante aprimoramento, introduzimos ali, o método T.W.I. (Training Withing Industry) interessante e prático esquema americano que visa o ensino correto de um trabalho, o aperfeiçoamento dos processos de sua execução e as relaçōes humanas no mesmo, método que, segundo depoimento de seus representantes no país, tivemos a primazia de aplicar em entidade pública, no Brasil. 
Concluindo as considerações sôbre o tema que vimos desenvolvendo, podemos afirmar com convicção, o valor real a ser atribuído aos meis exequíveis que proporcionem o apuro, ou desenvolvem as faculdades funcionais do pessoal do Hospital. A instituição de condições para êsse fim, notadamente no proprio ambiente de trabalho, apresenta entre outras, a excelsa vantagem de atribuir ao profissional, disposição psicológica para desempenhar a sua tarefa. Os exemplos bem o demonstram. Se as peculiaridades do Hospital dos Servidores do Estado permitiram a obtenção de resultados tão positivos, certo é que, quaisquer que sejam as características de uma entidade hospitalar, é o seu pessoal passível de ser submetido a métodos racionais de adestramento técnico e de desenvolvìmento de faculdades e atributos funcionais.

Consideramos mesmo, deva ser ebjeto de recomendação dêste Congresso, a instituição de normas que visem o permanente aprimoramento do pessoal que serve no hospital. Consideramos igualmente, mereça a matéria estar inrluícla na pauta da Associação Brasileira de Hospitais como ponto de relêvo na orientação a ser cumprida pelas organizações hospitalares do País.

\section{RESUMO}

O autor situa o grau de preparo técnico em geral, do pessoal hospitalar nos paises de elevado e baixo padrão econômico, associando a êsse fator, entre outros, os desníveis respectivos.

Demonstra como a formação técnica adequada requer condições materiais compativeis, o laboratório, a oficina, o instrumental do exercício prático, não prescindindo embora, de uma apropriada instrução doutrinária.

Anota o regime pedagógico vigente no preparo técnico-profissional, salientando o seu caráter predominantemente teórico, embora realçando a boa qualidade do ensino básico e a boa conceituação das escolas de formação de profissionais de hospital.

Considera imprescindível deva o hospital complementar, em sistema integrativo e bem definido, com os centros de ensino, a formação do pessoal técnico.

Assinala a importância do hospital funcional se constituir em escola ativa, devendo ser devidamente preparado para êsse mister.

Recomenda a revisão do regime didático, a fim de se estabelecer o sistema integrativo mencionado, codificando-se os princípios atinentes ao preparo do pessoal técnico e regulamentando-se os órgãos que devem compor êsse sistema.

Frisa a importância de se implantar esquemas racionais de treinamento do pessoal em serviço no hospital, como medida destinada não só ao apuro profissional como atenuação da acentuada carência de pessoal habilitado, experimentada pelas nossas organizações hospitalares. Considera ser de esplêndidos efeitos, a aplicação de programa com êsse objetivo, recomendando a sua extensão, inclusive, ao pessoal não técnico do hospital. Tece várias 
considerações a respeito, havendo criado condições nos Serviços que tem dirigido, para o aprimoramento dos servidores, com êxito que documenta.

A propósito, expõe experiência própria, comentando plano que teve oportunidade de executar no Hospital dos Servidores do Estado, quando na sua direção, ocasião em que criou diversos departamentos destinados àquêle fim, como labcratórios experimentais de medicina e cirurgia, escolas de auxiliares de enfermagem, e etc., abrindo largo campo ao aperfeiçoamento do pessoal que ali serve, conforme discrimina no texto do seu trabalho.

Conclui, realçando a exequibilidade da aplicação, em qualquer tipo de entidade hospitalar, de sistemas que visem o constante aperfeiçoamento do nessoal hospitalar, julgando deva ser recomendação dêste Congresso a adoção generalizada dessa prática.

\section{CONCLUSŌES}

A formação do pessoal técnico requer a instituição de sistema integrativo dos centros de ensino especializado com as células hospitalares.

Hospitais funcionais deverão se constituir em núcleos de complementa:ão do preparo técnico do pessoal.

Impõe-se o estabelecimento da codificação dos princípios e condições pedagógicas a serem cumpridas pela Escola e pelo Hospital, na formação do pessoal técnico.

E indicado estabelecer no hospital, regime racional permanente de treinamento do pessoal em serviço, de quaisquer categorias. ativa.

E importante fixar o conceito do hospital moderno ao sentido de escola

A formação técnico profissional para uma organização hospitalar de alto padräo requer o constante aprimoramento do pessoal que the é destinado.

\section{CONCLUSIONS}

1. The training of specialized personnel requires the institution of a system integrating the centres of special teaching with the hospital units.

2. Functional hospitals should become nuclei of complementary training of specialized personnel.

3. It should be promoted a codification of pedagogical principles and practices to be adopted by both the schools and the hospitals in the training of specialized personnel.

4. A rational, permanent system of in-service training of employees of any tipe should be established in the hospitals.

5. It is necessary to instill in the modern hospital the ideas of progressive education.

6. Professional training for hospitals of high level require the permanent development of its personnel. 